\title{
A Case Report on Jeune Syndrome in a Three Month Old Infant
}

\author{
BEGUM SHARIFUN NAHER ${ }^{1}$, BITHI RANI SAHA ${ }^{2}$, KANIZ BATUL NAIMA $^{3}$
}

\section{Introduction:}

Jeune syndrome (Asphyxiating thoracic dystrophy) is a rare autosomal recessive skeletal dysplasia characterized by small thorax, short ribs and polydactyly. International Working Group on Constitutional Diseases of Bone classified short rib and polydactyly syndrome into 6 types: type 1 (Saldino- Noonan), type 11 (Magewski), type III (VermaNaumoff), type IV (Beemer langer), type $\mathrm{V}$ (asphyxiating thoracic dystrophy ) and type VI (chondroectodermal dysplasia) (Ellis van Creveld) syndrome. Type 1-IV are lethal, however asphyxiating thoracic dystrophy (ATD) and Ellis van Creveld syndromes which have often but not always lethal character ${ }^{1}$.

Asphyxiating thoracic dystrophy was first described in 1955 by Jeune et al in two siblings with severely narrow thorax. Jeune syndrome is known to be genetically heterogeneous. A locus has been identified on chromosome $15 q 13$ in which recently mutation is found in the IFT80 gene ${ }^{2,3}$.

Jeune syndrome is a disorder of bone growth characterized by a narrow and short-rib thorax, short sternum and hypoplastic iliac wings. The long bones are either normal or mildly shortened ${ }^{4,5}$. This syndrome is a rare multisystem skeletal dysplasia estimated to occur in 1 per 1,00,000-1,30,000 live births. ${ }^{6}$

The small thorax often results in respiratory distress and recurrent respiratory infection in the neonatal period and infancy. There is wide spectrum of symptoms beginning from a latent form to lethal condition. In severe cases the progressive respiratory failure may lead to death of neonate. Progressive renal failure is typical for mild form of asphyxiating thoracic dystrophy ${ }^{5}$.

In $60-80 \%$ of Jeune syndrome prognosis is poor and often leads to early death of infant ${ }^{7}$. We describe here one such case with the diagnosis based on clinical and radiological findings.

1. Associate Professor, Neonatology, SSMC Mitford, Dhaka

2. MO, Shishu Shasthyo Foundation, Mirpur

3. MO, Dhaka Paediatric Neonatal General Hospital

Correspondence to: Dr. Begum Sharifun Naher, Cell: 01819263555,

E-mail: dr.sharifun_nahar@yahoo.com

\section{Case report:}

A 3 month old male baby, second issue of a nonconsanguineous parents coming from a middle class family of Faridpur got admitted to a private clinic with the complaints of fever, cough and cold with respiratory distress for last 5 days. There was history of convulsion in the form of rolling of eye ball and bluish discoloration of skin during attack. He had recurrent episodes of such type of illness in the past. Mother was on regular antenatal check up and her antenatal health was good. The baby was delivered at term in a hospital by lower uterine cesarean section (LUCS). Baby was asphyxiated at birth. He was on exclusive breast feeding and was immunized as per EPI schedule. On examination he was dyspnic, fontanel was not bulged, cyanosis disappeared with oxygen. He was restless. Chest was deformed, narrow and depressed centrally, severe chest indrawing was present. There was polydactyly on the left hand and right sided polydactyly was autoamputated after birth. His respiratory rate was $52 / \mathrm{min}$, heart rate was normal and temperature was 99 degree C. Heart sounds were normal and there was no added sound on auscultation. Occipitofrontal circumference(OFC) was $40 \mathrm{~cm}$ which was normal for his age. BCG mark was present. On abdominal examination liver and spleen were palpable. Other systems did not reveal any abnormality. On investigation haemoglobin was $11 \mathrm{gm} /$ dl WBC count was $12500 / \mathrm{cmm}$ and platelet count was normal. Neutrophil count was $78 \%$ but other cell count was normal CRP was $12 \mathrm{mg} / \mathrm{l}$ (positive). Serum electrolyte was normal Calcium was $9.2 \mathrm{mg} / \mathrm{dl}$. Lumbar puncture was done and CSF study did not show any abnormality. Echocardiography was also normal. USG of abdomen showed that liver was pushed down and enlarged. On the other hand slightly raised texture of cerebral hemispheres were found on USG of brain; which may be due to hypoxia as per the comment of sonologist. X-Ray of the chest revealed small chest, high up clavicle, horizontal ribs and segmental consolidation in the right upper lobe. So on the basis of clinical examination finding and radiological evidence the patient was diagnosed as Asphyxiating thoracic dystrophy (ATD) with acute respiratory tract infection. He was managed with $\mathrm{O}_{2}$ supplementation, antibiotics and anticonvulsants. $\mathrm{He}$ was discharged with proper counseling and advice after recovery from respiratory tract infection but the patient did not come for follow up visit to us. 


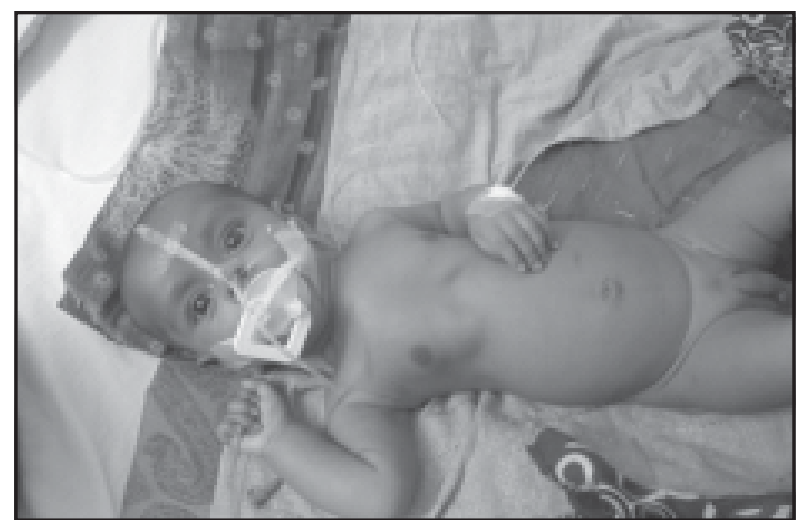

Fig.-1: Photograph showing narrow centrally depressed small bell shaped chest

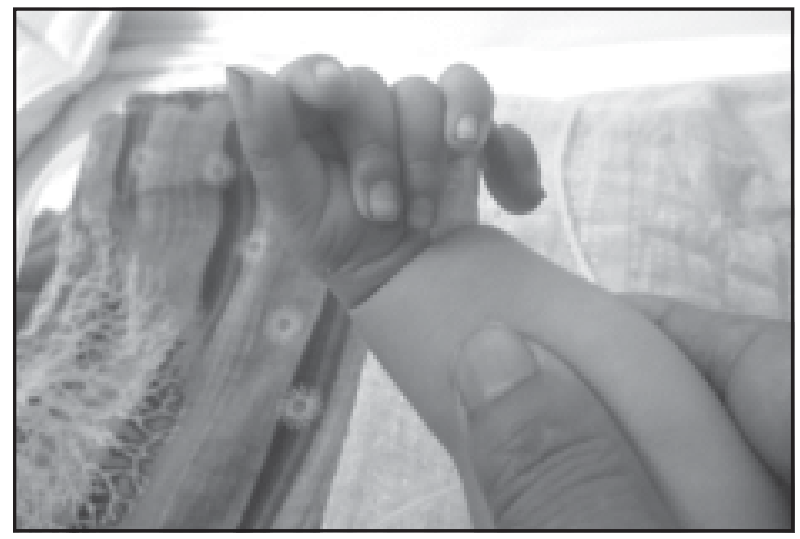

Fig.-2: Photograph showing polydactyly

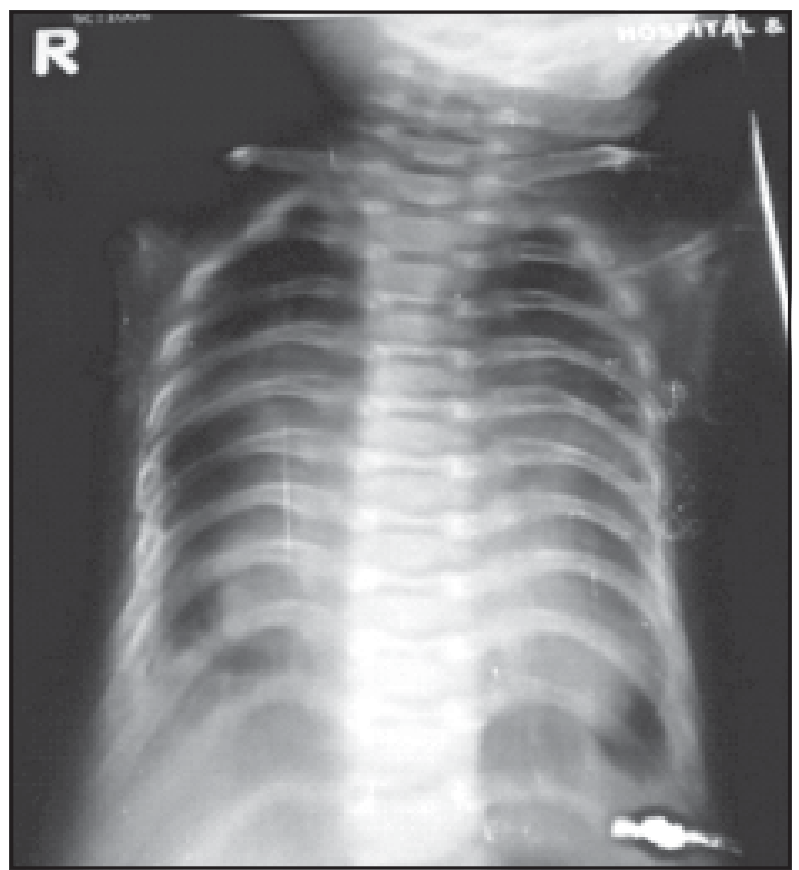

Fig.-3: $X$-ray chest showing small chest, high up clavicle, horizontal and short rib

\section{Discussion:}

Clinically, ATD is characterized by a small, narrow chest and variable limb shortness. Associated congenital abnormalities can be postaxial polydactyly of both hands and/ or feet 20\%. Typical radiographic findings include a narrow, bell shaped thorax with short, horizontally oriented ribs and irregular costochondral junction, elevated clavicle, short iliac bones with a typical trident appearance of the acetabula, relatively short and wide long bones of the extremities and hypoplastic phalanges of both hands and feet with cone shaped epiphyses. In our case short limbs were not found but presentation with respiratory problem with severe distress, hypoxia and cyanosis and bell shaped chest with bilateral postaxial polydactyly on clinical examination and typical radiological finding of elevated clavicle, horizontal and short ribs helped us to come to diagnosis.

The radiographic findings are so typical that distinction from other skeletal dysplasia except Ellis van Creveld syndrome is not difficult. In Ellis van Creveld syndrome the appearance of the pelvis is indistinguishable but the involvement of the thorax is less pronounced ${ }^{8,9}$.

Some authors state that the diagnosis of Jeune syndrome is possible just around 17-18 weeks of gestation ${ }^{10}$. Nowadays with dynamic development of ultra-sound techniques earlier diagnosis is possible; especially in severe cases of this disease.

Jeune syndrome is sometimes compatible with life although respiratory failure and infections are often fatal during infancy. For those patients who survive infancy, the thorax tends to revert to normal with improving respiratory function. This suggests that the lungs have a normal growth potential and the respiratory problems are secondary to restricted rib cage deformity ${ }^{7}$.In milder types of Jeune syndrome it is possible to surgically expand thoracic cavity to prevent respiratory distress ${ }^{11}$.

Recently there has been some research on the use of computer tomography in diagnosing Jeune syndrome ${ }^{12}$.

\section{Conclusion:}

It is important to establish the correct diagnosis of ATD since it might recur within the same family.

\section{References:}

1. International Working Group on Constitutional Diseases of Bone (1998). International Nomenclature and Classification of the Osteochondro dysplasias . Am J. Med. Genet 1997; 79: 376-82. 
2. Jeune M, Beraud C, Carron R. Dystrophie Thoracique asphyxiante de caract'ere. Arch Fr Pediatr 1955; 12: 886.

3. Morgan NV, Bacchelli C, Gissen P, Morton J, Ferrero GB, Silengozm et al. A locus for asphyxiating thoracic dystrophy, ATD maps to chromosomes 15q13. J Med Genet 2003; 40: 431-35.

4. Den Hollander NS, Robben SGF. Hoogeboom AJ.M. Early prenatal sonographic diagnosis and follow up of Jeune syndrome. Ultrasound Obstet. Gynecol 2001; 18: 378-83.

5. Ho N.C, Francomano CA, Van Allen M. Jeune (Asphyxiating Thoracic Dystrophy) and ShortRib Polydactyly Typelll (Verma-Naumoff) are variants of the same disorder. Am. J. Med. Genet 2000; 90: 310-14.

6. Oberklaid F, Danks DM, Mayne V, Campbell P, Asphyxiating thoracic dysplasia: clinical, radiological and pathological information on 10 patients. Arch Dis Child 1977; 52: 758-65.
7. De Vries J, Yntema JL, van Die CE, Crama N, Cornelissen EAM, Hamel BCJ. Jeune syndrome: description of 13 cases and a proposal for followup protocol.Eur J Pediatr 2010; 169: 77-88.

8. Herdman RC, Langer LO. The thoracic asphyxiant dystrophy and renal disease. Am J Dis Child 1968; 116: 192-201.

9. Pirnar T, Neuhause EBD. Asphyxiating thoracic dystrophy of the newborn. Am J Roentgen 1966; 98:358-64.

10. Schinzel A, Salvoldelli G, Bringer J. Prenatal sonographic diagnosis of Jeune syndrome. Radiology 1985; 154: 777-8.

11. Conroy E, Eustace N, Mccormarck D. Sternoplasty and Rib Distraction in neonatal Jeune Syndrome. J Pediatr. Orthop. 2010; 30 (6): 527-30.

12. Yamada T, Nishimura G, Nishida K. Prenatal diagnosis of short- rib polydactyly syndrome type 3 by three- dimensional helical computed tomography. J Obstet. Gynaecol Res. 2011; 37(2): 151-5. 